
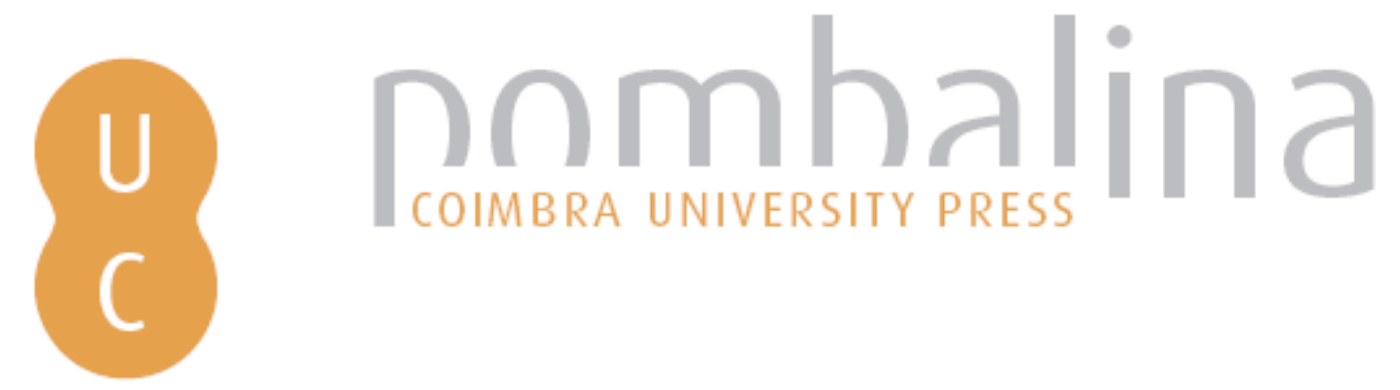

\title{
O projecto "Organização do espólio de Carolina Michaëlis de Vasconcelos e catalogação do respectivo Epistolário"
}
Autor(es):
Delille, Maria Manuela Gouveia
Publicado por: Imprensa da Universidade de Coimbra
URL
persistente:
URI:http://hdl.handle.net/10316.2/36994
DOI:
DOI:http://dx.doi.org/10.14195/978-989-26-1045-0_23
Accessed : $\quad$ 26-Apr-2023 11:33:01

A navegação consulta e descarregamento dos títulos inseridos nas Bibliotecas Digitais UC Digitalis, UC Pombalina e UC Impactum, pressupõem a aceitação plena e sem reservas dos Termos e Condições de Uso destas Bibliotecas Digitais, disponíveis em https://digitalis.uc.pt/pt-pt/termos.

Conforme exposto nos referidos Termos e Condições de Uso, o descarregamento de títulos de acesso restrito requer uma licença válida de autorização devendo o utilizador aceder ao(s) documento(s) a partir de um endereço de IP da instituição detentora da supramencionada licença.

Ao utilizador é apenas permitido o descarregamento para uso pessoal, pelo que o emprego do(s) título(s) descarregado(s) para outro fim, designadamente comercial, carece de autorização do respetivo autor ou editor da obra.

Na medida em que todas as obras da UC Digitalis se encontram protegidas pelo Código do Direito de Autor e Direitos Conexos e demais legislação aplicável, toda a cópia, parcial ou total, deste documento, nos casos em que é legalmente admitida, deverá conter ou fazer-se acompanhar por este aviso.

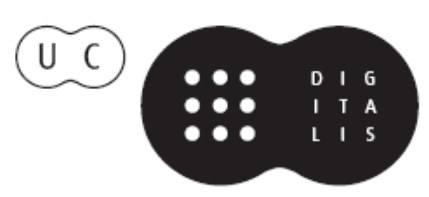



Tendo como pano de fundo as Comemorações dos seus 500 anos, a Biblioteca Geral da Universidade de Coimbra organizou um Congresso Internacional subordinado ao tema "A Biblioteca da Universidade: permanência e metamorfoses", que teve lugar nos dias 16, 17 e 18 de janeiro de 2014, no auditório da Reitoria da Universidade de Coimbra.

O objetivo maior desta reunião científica foi o de refletir sobre o presente e o futuro das bibliotecas que servem públicos universitários. Numa outra vertente, procurou chamar-se a atenção para a importância de que a Biblioteca se reveste, tendo em vista o progresso do conhecimento técnico e científico. Por último, o Congresso pretendeu instituir-se como oportunidade de reflexão prospetiva e como lugar de encontro entre as sensibilidades de todos os que trabalham profissionalmente com livros e com outros suportes de natureza bibliográfica.

Nesse sentido, foram apresentadas Conferências, Mesas Redondas e sessões de Testemunhos em torno de temas como o valor das bibliotecas universitárias, a biblioteca universitária em contexto; as mudanças e os desafios; a biblioteca universitária e a sociedade da informação e conhecimento; o impacto do acesso aberto na comunidade científica, e as bibliotecas digitais. 


\section{O PROJECTO “ORGANIZAÇÃO DO ESPÓLIO \\ DECAROLINA MICHÄ̈LIS DE VASCONCELOS ECATALOGAÇÃO DO RESPCTIVO EPISTOLÁRIO»}

Começo por agradecer ao Professor Doutor José Augusto Cardoso Bernardes, Director da Biblioteca Geral da Universidade de Coimbra (BGUC) e meu prezado Colega, o convite para participar neste Congresso, convite esse que aceitei com muito gosto porque me daria ensejo a recordar as gratas memórias que, desde os meus tempos de Assistente da Faculdade de Letras (anos 60 do século passado), guardo da nossa Biblioteca. Por manifesta falta de tempo, não irei hoje, porém, dispersar-me por memórias antigas, mas sim procurar dar testemunho de um trabalho relativamente recente aqui desenvolvido, designadamente o Projecto intitulado "Organização do Espólio de Carolina Michaëlis de Vasconcelos e Catalogação do respectivo Epistolário”, o qual decorreu, sob a minha coordenação científica, entre Novembro de 2009 e os primeiros meses de 2012. Parece-me tanto mais oportuno o presente testemunho porque na fase final do Projecto, que coincidiu com a mudança de Direcção da Biblioteca, não se proporcionou a organização de uma sessão pública em que se desse a devida conta do trabalho realizado.

O Projecto em causa nasceu no contexto de um Projecto mais amplo denominado "Carolina Michaëlis e Joaquim de Vasconcelos: um Encontro de Culturas e de Saberes”, que, sob a coordenação geral do Senhor Engenheiro Carlos Michaëlis de Vasconcellos, bisneto do casal, do Senhor Dr. Luís Cabral, representante da Câmara Municipal do Porto, e de mim própria, começou a ser concebido em finais de 2008/inícios de 2009 e envolveu nesse ano de 2009 e nos dois anos seguintes diversas instituições e entidades de Coimbra e do Porto, abrangendo a realização de três 
Exposições e de um Colóquio Internacional sobre a vida e a obra desses dois eruditos, que se distinguiram no meio cultural, científico e artístico da sua época e deixaram rasto para tempos futuros ${ }^{1}$.

O Projecto de Organização do Espólio e Catalogação do Epistolário foi apresentado através da BGUC ao concurso anual da Fundação Calouste Gulbenkian (FCG) para recuperação, tratamento e organização de acervos documentais, e - tendo obtido aprovação em meados de 2009 - pôde começar a ser executado em Novembro desse mesmo ano.

A coordenação institucional foi assumida pelo então Director da Biblioteca, Professor Doutor Carlos Fiolhais, a coordenação científica esteve a meu cargo, a da gestão financeira a cargo do Doutor Jorge Pais de Sousa e a coordenação técnica foi assegurada pela Bibliotecária Dr. ${ }^{a}$ Isabel João Ramires. A FCG financiou uma bolseira durante um ano, a Dr. ${ }^{a}$ Dina Dinis, e por cinco meses segunda bolseira, a Dr. ${ }^{a}$ Teresa Montes. Por minha iniciativa e graças ao voluntariado de alguns Colegas interessados na matéria tratada, três Centros de Investigação com sede na Faculdade de Letras da Universidade de Coimbra (FLUC) - o Centro de Investigação em Estudos Germanísticos (CIEG), o Centro de Estudos de Linguística Geral e Aplicada (CELGA) e o Centro de Literatura Portuguesa (CLP) -, o Centro Interuniversitário de Estudos Camonianos (CIEC), sediado na BGUC, e ainda o Centro de Investigação Transdisciplinar Cultura Espaço e Memória (CITCEM), integrado na Faculdade de Letras da Universidade do Porto $^{2}$, prontificaram-se a agir como entidades parceiras da BGUC, prestando apoio científico e/ou financeiro ao Projecto, o qual compreendeu o tratamento do Espólio documental e, em paralelo, a catalogação do respectivo Epistolário.

${ }^{1}$ Vd. uma descrição mais completa do Projecto, in: DeLILLE, Maria Manuela Gouveia Catálogo da Exposição Bibliográfica e Documental: "A Vida e a Obra de Carolina Michaëlis de Vasconcelos. Evocação e Homenagem", Coimbra: Imprensa da Universidade, 2009. p. 31, e "Exposição Bibliográfica e Documental - A Vida e a Obra de Carolina Michaëlis de Vasconcelos. Evocação e Homenagem", Rua Larga. n. ${ }^{\circ}$ 27, Janeiro de 2010, pp. 27-30.

2 O apoio financeiro do CITCEM, do CIEC e do CIEG permitiu prolongar por mais quatro meses e meio (respectivamente, de Setembro a Novembro de 2010, de Janeiro a Março de 2011 e de 13 a 31 de Maio de 2011) o tempo de trabalho da segunda bolseira. 
Antes da descrição necessariamente sumária das duas partes nucleares do Projecto, permitam-me uma breve história da aquisição do Espólio de Carolina Michaëlis de Vasconcelos pela BGUC.

Após a compra da biblioteca particular de Carolina Michaëlis de Vasconcelos e Joaquim de Vasconcelos à Família pela FLUC em 1944, os manuscritos de Carolina Michaëlis de Vasconcelos foram, em 1945, doados, juntamente com os de Joaquim de Vasconcelos, à mesma Faculdade pelo Senhor Engenheiro Joaquim Ernesto de Vasconcelos, neto de Carolina Michaëlis de Vasconcelos e de Joaquim de Vasconcelos. Todo esse Espólio (juntamente com a maioria dos volumes pertencentes à biblioteca particular de Carolina Michaëlis de Vasconcelos e de Joaquim de Vasconcelos) transitou em 1951 do velho edifício da FLUC para o novo, onde permaneceu por tratar durante mais de duas dezenas de anos. Em 1975, os manuscritos acabaram por ser entregues pela FLUC à BGUC, tendo-se aí mantido, também sem tratamento adequado (ou com tentativas esporádicas de inventariação muito parcial e empírica) até ao ano de 2009. Diga-se ainda que, nos anos 90, a BGUC adquiriu em leilão, por iniciativa do então seu Director, o Professor Doutor Aníbal Pinto de Castro, um significativo conjunto de cartas dirigidas a Carolina Michaëlis de Vasconcelos da autoria de escritores portugueses (alguns deles membros da Geração de 70) e de romanistas italianos, que em muito veio enriquecer o Epistolário.

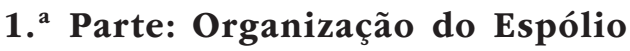 de Carolina Michaëlis de Vasconcelos}

A realização da Primeira Parte do Projecto - Organização do Espólio de Carolina Michaëlis de Vasconcelos - compreendeu três fases:

\section{1. ${ }^{\mathrm{a}}$ Fase}

A 1. ${ }^{\mathrm{a}}$ fase, que decorreu entre Novembro de 2009 e Maio de 2010, consistiu na macrotriagem de todo o conjunto documental, constituído 
por documentos produzidos e reunidos por Carolina Michaëlis no decurso da sua vida e da sua actividade científica, conjunto esse que incluía documentação inédita e publicada, de dimensão e tipologia muito diversas:

- manuscritos da Autora (planos de obras e artigos, rascunhos, originais para impressão, apontamentos pessoais em cadernos ou em folhas avulsas, notas de leitura, referências bibliográficas, comentários, glossários em fichas e em cadernos, listas de autores, anotações em fragmentos de papel);

- textos impressos da Autora (provas tipográficas, recensões, impressos com anotações autógrafas);

- manuscritos e impressos de terceiros;

- retratos.

Esse conjunto apresentava-se num estado altamente desordenado, para não dizer caótico. Na verdade, ele fora acondicionado em pastas ou maços (ca. 75), com um número muito variável de documentos cada. Regra geral, constatou-se o carácter altamente heterogéneo das várias pastas e a sua desorganização intrínseca.

$\mathrm{Na}$ maioria dos casos as pastas ou maços originais em que as peças se encontravam não traziam qualquer identificação dos conteúdos; nos casos em que existiam referências nas etiquetas ou anotações sobre as pastas, estas não correspondiam ao conteúdo das mesmas. Na mesma pasta e nos vários conjuntos documentais que a integravam acumulavam-se, p. ex., apontamentos, rascunhos e originais (várias versões), não ordenados, de um ou vários textos publicados, misturados com papéis de carácter particular, com facturas, recibos, folhetos, e até com cartas ou rascunhos de cartas.

Após definição das principais áreas sobre que incidiram os estudos científicos e a actividade pedagógica de Carolina Michaëlis de Vasconcelos, partindo sempre da bibliografia michaëliana bem como dos dados biográficos da Autora, procurei elaborar uma grelha interna, em que alistei dez séries temáticas e respectivas subséries, destinada a servir de guia na identificação e organização do material do Espólio: 
Série A: Estudos de Línguas Românicas, com especial incidência nas Línguas Hispânicas, muito especialmente na Língua Portuguesa

Principais áreas de investigação:

- Etimologia

- Lexicologia

- Fonética Histórica

- Morfologia e Sintaxe

- Semântica

- Ortografia

- Outras

Série B: Estudos Literários

B.1. Literatura portuguesa

B.1.1. Literatura medieval

- Literatura trovadoresca galaico-portuguesa/Cancioneiros/Romanceiro

- Crónicas

- Prosa narrativa ficcional

- Poesia palaciana/Cancioneiro Geral de Garcia de Resende

B.1.2. Gil Vicente e Escola Vicentina

B.1.3. Literatura renascentista

- Bernardim Ribeiro/Cristóvão Falcão

- Sá de Miranda

- Francisco de Morais

- Jorge Ferreira de Vasconcelos

- Pêro de Andrade Caminha

- Jorge de Montemayor

- Luís de Camões

- António Ferreira

- Frei Agostinho da Cruz

- Diogo Bernardes

B.1.4. Literatura do século XVII

- Francisco Rodrigues Lobo

- Francisco Manuel de Melo 
B.1.5. Literaturas setecentista e oitocentista

B.1.6. Fim-de-século/Neo-romantismo

B.1.7. História da Literatura Portuguesa e Antologias de Poesia Portuguesa

B.2. Literatura espanhola

B.3. Literatura hispano-portuguesa

B.4. Outras literaturas românicas

B. 5. Outras literaturas

\section{Série C: Estudos Etnográficos}

Série D: Estudos Históricos (e.o. figuras históricas como: Inês de Castro, o Condestável D. Pedro, a Infanta D. Maria, Públia Hortênsia de Castro, Uriel da Costa), Estudos Culturais e Outros

Série E: Estudos sobre a Mulher

Série F: Estudos sobre Deveres Maternos, Educação Infantil (Ensino e Literatura)

Série G: Actividade Pedagógica na Faculdade de Letras da Universidade de Coimbra

(Lições de Filologia Portuguesa, Filologia Românica, Gramática Comparada das Línguas Românicas, Língua e Literatura Alemãs I, II e III e arguições de teses)

Série H: Colaboração em Dicionários Luso-Alemães e em Manuais de Conversação de Alemão-Português

Série I: Notas autobiográficas, bibliográficas, retratos e outra documentação

Série J: Varia (manuscritos e impressos)

J.1. Cadernos de apontamentos 
J.2. Manuscritos de terceiros

J.3. Impressos, números avulsos de jornais e revistas portuguesas e de jornais e revistas alemãs, espanholas e britânicas

J.4. Recortes de jornais

J.5. Monografias e separatas de terceiros

J.6. Bilhetes, cartazes, programas, prospectos e catálogos de livreiros

J.7. Documentos vários por classificar

J.8. Documentos não pertinentes

À medida que íamos vendo um a um os documentos de cada uma das pastas, procedia-se à sua distribuição por estes dez núcleos ou séries temáticas e respectivas subséries.

Os trabalhos supra-referidos foram efectuados por mim e pela Dr. ${ }^{a}$ Isabel João Ramires com a colaboração assídua do Professor Doutor João Nuno Corrêa-Cardoso e da Dr. ${ }^{a}$ Maria Alice Amado Mendes, professora aposentada da Escola Secundária Infanta D. Maria, e o apoio pontual da Bibliotecária Dr. ${ }^{a}$ Graça Toscano e da bolseira Dr. ${ }^{a}$ Dina Dinis.

\section{2. ${ }^{\mathrm{a}}$ Fase}

- De Junho de 2010 a Abril de 2011: Análise da documentação seriada

Uma vez seriados, os processos foram distribuídos para análise por mim, pela Dr. ${ }^{a}$ Isabel João Ramires e pelos membros dos Centros de Investigação que colaboraram no Projecto, nomeadamente pelos Professores Doutores Cristina Martins, Isabel Santos e João Nuno Corrêa-Cardoso do CELGA, pela Professora Doutora Ana Maria Machado e os Doutores Alexia Dotras Bravo e Sara Augusto do CLP, tendo todos podido contar com o apoio das bolseiras Dr. ${ }^{a}$ Dina Dinis e Dr. ${ }^{a}$ Teresa Montes.

Dessa análise resultou a indicação mais precisa da série ou subsérie em que os documentos deviam ficar integrados e, muito frequentemente, não só a indicação da matéria dos documentos e a identificação dos textos, 
mas também, sempre que possível, a menção da respectiva publicação de Carolina Michaëlis de Vasconcelos.

Encontram-se descritos 1.177 conjuntos documentais, constituídos por um ou mais documentos.

\section{3. ${ }^{\mathbf{a}}$ Fase}

- De Maio de 2011 até Março de 2012: Acondicionamento e inventário

Tarefa executada exclusivamente pela Dr. ${ }^{a}$ Isabel João Ramires: acondicionamento dos documentos em capilhas (papel acid-free) e das séries em caixas acid-free. No total, 29 caixas + 1 caixa de jornais. Há séries que ocupam duas ou três caixas.

\section{Parte: Catalogação do Epistolário de Carolina Michaëlis de Vasconcelos}

\section{Catalogação online - De Novembro 2009 a Dezembro de 2011}

No início do Projecto sobre o Fundo documental de Carolina Michaëlis de Vasconcelos estavam contabilizadas como pertencentes ao Epistolário cerca de 724 peças (cartas, bilhetes, bilhetes-postais, telegramas, cartões de visita). No decurso da catalogação do Epistolário vieram juntar-se a este número mais 764 itens, resultantes da triagem dos documentos do Espólio e provenientes de outros Fundos em tratamento na BGUC, num total de 1488 registos bibliográficos, incluindo correspondência recebida e cartas de terceiros, e excluindo rascunhos de cartas de Carolina Michaëlis de Vasconcelos e sobrescritos sem conteúdo endereçados a/por Carolina Michaëlis de Vasconcelos, cuja contagem não é ainda definitiva.

Nos primeiros meses foi dada ênfase ao tratamento técnico da correspondência, numa tentativa de disponibilizar rapidamente ao público a informação sobre a existência do Epistolário e respectivos corresponden- 
tes. Para esse efeito, procedeu-se a uma descrição básica de cada item, tendo sido possível avançar rapidamente com a catalogação de toda a correspondência recebida, a qual ficou concluída em Novembro de 2010. No entanto, a partir de Maio de 2010, no sentido de melhor explorar a riqueza do Epistolário, muito especialmente a chamada "correspondência erudita" (Gelehrtenkorrespondenz), de manifesto interesse e utilidade na perspectiva dos investigadores, procedeu-se a uma análise mais atenta do conteúdo dos documentos e à elaboração dos respectivos resumos. Tal implicou uma leitura minuciosa das cartas, bem como um trabalho moroso de investigação relativo à identificação e sucinta caracterização dos emissores/autores, bem como de obras e temas relevantes. É de sublinhar a multiplicidade de assuntos encontrados, assim como as dificuldades impostas pelas caligrafias apresentadas na maioria dos manuscritos, os quais se encontram em diversas línguas (português, alemão, espanhol, italiano, francês e inglês).

O catálogo do Epistolário de Carolina Michaëlis de Vasconcelos encontra-se disponível no Catálogo Integrado das bibliotecas da Universidade de Coimbra (SIIB): http://webopac.sib.uc.pt.

No índice de autores existente antes de 2009, com 236 autores identificados, foram corrigidos alguns dos nomes e acrescentados ao longo do projecto mais 108 novos autores, num total de 344 correspondentes. Quanto às línguas utilizadas nesta correspondência, registámos os seguintes números: 976 espécies em português, 219 em alemão, 90 em espanhol, 78 em inglês, 63 em francês e 59 em italiano.

A criação dos registos bibliográficos no sistema on line do Catálogo Integrado das Bibliotecas da Universidade de Coimbra esteve a cargo da Dr. ${ }^{a}$ Isabel João Ramires e das bolseiras Dras. Dina Dinis e Teresa Montes, assim como a análise e resumos da correspondência em português, espanhol e inglês, com o apoio das Dras. Maria Alice Amado Mendes e Maria Celeste Saraiva de Sousa. Os resumos da correspondência em língua alemã, e alguns em língua espanhola, foram elaborados pelo Professor Doutor Karl Heinz Delille e por mim (216 itens) e pelo Professor Doutor Rogério Madeira (3 itens), os resumos da correspondência em língua francesa, pelo Professor João Nuno Corrêa-Cardoso e pela Dr. ${ }^{a}$ Isabel João Ramires (63 itens), a 
correspondência em língua italiana, pelo Doutor Alberto Sismondini (38 itens) e pelos Professores Doutores João Nuno Corrêa-Cardoso (9 itens) e Manuel Ferro (12 itens).

A descrição catalográfica e os resumos da correspondência foram revistos pela Dr. ${ }^{a}$ Isabel João Ramires e por mim, tendo a revisão ficado concluída em finais de 2011.

$\mathrm{O}$ acondicionamento das cartas (da inteira responsabilidade da $\mathrm{Dr}^{{ }^{a}}$ Isabel João Ramires) foi feito em capilhas (papel acid free) com uma capilha por autor. As capilhas estão acondicionadas em cinco caixas acid free, quatro de correspondência recebida e uma com rascunhos de cartas e correspondência de terceiros.

Concluindo: A organização e classificação do espólio de Carolina Michaëlis de Vasconcelos - que, como Professora da Faculdade de Letras da Universidade de Coimbra, entre 1912 e 1925, foi a primeira mulher a ocupar uma cátedra numa universidade portuguesa e um dos maiores vultos da Filologia Românica a nível nacional e internacional - abre indubitavelmente numerosas pistas de investigação aos estudiosos, veiculando-lhes informação minuciosa, quer sobre a génese e conteúdo da obra monumental michaëliana, que constitui um inexcedível exemplo do rigoroso método histórico-comparativo da ciência filológica germânica daquela época, quer sobre a acção exercida por esta grande erudita como mediadora entre a Alemanha e Portugal no campo das letras e da cultura em geral. No presente Espólio, reflexo da vida pessoal e profissional de $\mathrm{D}$. Carolina, da sua rede de relações sociais e intelectuais, e da sua acção cívica, encontram-se ainda, nomeadamente sob este último aspecto, diversos documentos e apontamentos inéditos que testemunham o seu empenho em prol da instrução e da educação da Mulher e da Criança em Portugal, em finais do século XIX e nas primeiras décadas do século XX.

Seja por último sublinhada a especial relevância, no conjunto do Espólio, do extenso núcleo de correspondência trocada com importantes figuras do meio literário e académico português e estrangeiro. 
Entre os escritores e romanistas estrangeiros destacam-se os nomes de Aubrey Bell, Tommaso Cannizzaro, Arturo Farinelli, Foulché-Delbosc, Carl Goldbeck, Gustav Gröber, Henry Lang, Menéndez y Pelayo, Menéndez Pidal, Alfred Morel-Fatio, Antonio Padula, Edgar Prestage, Joseph Priebsch, Karl Gustav Vollmöller, Eduard Wechssler. Quanto aos escritores, professores, académicos e eruditos portugueses, cumpre mencionar os seguintes: Joaquim de Araújo, Teófilo Braga, Agostinho de Campos, Cláudia de Campos, Alberto Osório de Castro, Eugénio de Castro, Joaquim de Carvalho, Maria Amália Vaz de Carvalho, Manuel Gonçalves Cerejeira, Adolfo Coelho, João da Providência Costa, Jaime Cortesão, Epifânio da Silva Dias, Manuel da Silva Gaio, Delfim Guimarães, Ricardo Jorge, Maximiano Lemos, Cândido Nazaré, José Joaquim Nunes, Ana de Castro Osório, Alfredo Pimenta, Antero de Quental, Olga Morais Sarmento, António Sérgio, José Leite de Vasconcelos, Gonçalves Viana, Afonso Lopes Vieira e Francisco Marques de Sousa Viterbo. 
José Augusto Cardoso Bernardes é Professor da Faculdade de Letras da Universidade de Coimbra e Diretor da Biblioteca Geral da Universidade

Ana Maria Eva Miguéis é coordenadora do Serviço Integrado das Bibliotecas da Universidade de Coimbra

Carla Ferreira é bibliotecária nos Serviços de Biblioteca e Documentação da Faculdade de Letras da Universidade de Coimbra. 


\section{Série Documentos}

Imprensa da Universidade de Coimbra

Coimbra University Press

2015

C •

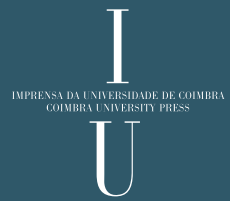

